\title{
EFFECT OF STARCH ADDITION ON THE PROPERTIES OF LOW DENSITY POLYETHYLENE FOR DEVELOPING ENVIRONMENTALLY DEGRADABLE PLASTIC BAGS
}

\author{
${ }^{1}$ Ruhul Amin M*., ${ }^{2}$ Basel F. Abu-Sharkh and ${ }^{2}$ Mamdouh Al-Harthi \\ ${ }^{1}$ Department of Chemical Engineering \\ Bangladesh University of Engineering \& Technology (BUET), Dhaka-1000, Bangladesh \\ ${ }^{2}$ King Fahd University of Petroleum \& Minerals, \\ P. O. Box 5050 Dhahran 31261, Kingdom of Saudi Arabia
}

\begin{abstract}
Starch is an inexpensive abundant product and is totally biodegradable in a wide variety of environments and allows the development of totally degradable products for specific market needs. We study the influence of starch on the degradation behavior of plastic films prepared by mixing the film grade polyethylene pellets with different amounts of starch. The mechanical strength of the polymer films were measured by Instron 5560 Tensile Testing Machine and observed that with the addition of starch mechanical strength decreases. As biodegradation rate increases with starch addition, 25 to $35 \%$ starch can be added safely in the plastic shopping bag without changing its strength significantly.
\end{abstract}

Keywords

Degradation; polyethylene; additive; starch; mechanical strength; DSC

\section{Introduction}

Starch-based materials today have the most relevant share of the total market of biodegradable materials from renewable resources, accounting for about $85-90 \%$ of such market. As already underlined main applications are in the sector of composting bags and loose-fillers. Starchbased carrier bags have been introduced in the market starting from the beginning of 1999. Starch-based materials in this market segment are mainly used as bags for fruits, vegetables and bread. The main advantage of starch-based films over traditional materials in the packaging of fruit and vegetables is breathability, which improves storage conditions ${ }^{1}$.

Roper et al. reviewed the chemical modification of classical polymers into photo- and chemo-degradable materials ${ }^{6}$. The study included physical mixing of $6-20 \%$ granular starch with polyethylene or polypropylene, coprocessing of more than $50 \%$ disintegrated starch with hydrophilic polymers like polyacrylate or polyvinylalcohol to biodegradable films for agricultural mulch or carrying bags.

Thermoplastic starch-based polymers are polymers made with at least $90 \%$ starch from renewable resources such as corn, potato, tapioca or wheat. Thermoplastic starches are based on gelatinized starch from different sources, for * Corresponding Author's Email : amin@ che.buet.ac.bd example, potato, corn, wheat or tapioca ${ }^{2}$. Rodlan-Carrillo et al. studied starch metabolites and enzymes during starch-based plastic polymer biodegradation by the white rot fungus Phanerochaete chrysosporium, grown in sugarcane bagasse pith in tubular reactors ${ }^{3}$. Kulshreshtha et al. reviewed some commercially available environment-friendly plastics ${ }^{4}$. Sitohy et al investigated degradability of different phodphorylated starch types (corn, rice, potato, corn amylose, and corn amylopectin) ${ }^{5}$. The plastic films prepared from phosphorylated corn showed both higher disintegration rate and a greater degradability by thermostable bacterial than the ones prepared from non-phosphorylated. These newly acquired properties can meet the increasing demand for biodegradable disposable plastic bags.

Natural starch fillers were commonly added to polyolefins to produce composites with certain degradability $^{7.8}$. However, the nominal adhesion between starch and polyolefins is poor, owing to the incompatibility

between the hydrophilic starch and hydrophobic polyolefins. Consequently, the introduction of unmodified starch to the thermoplastics generally results in the decrease of tensile strength and toughness. 
In this study, we investigate the influence of starch on the degradation behavior of plastic films prepared by mixing the film grade polyethylene pellets with different amounts of starch.

\section{EXPERIMENTAL}

\section{Materials}

The film grade low density polyethylene obtained from SABIC, Saudi Arabia and starch-based biodegradable additives Polystarch-N was supplied by Willow Ridge Co., USA.

\section{Sample Preparation}

Plastic films were prepared by first premixing the film grade polyethylene pellets with Polystarch-N additive. Additive loadings were $10,20,30$ and 40 percent mixed with pure polyethylene. Subsequently, the mixer was fed to an extruder to produces the film.

\section{Extrusion and Processing Condition}

The resulting "dry blend" was then extruded in a single screw extruder consisting of three heating sections and a die plate. The temperatures of the three heating zones of the barrel were set at $160^{\circ} \mathrm{C}$ and the temperature of the die section was set at $120^{\circ} \mathrm{C}$.

\section{Sample Analysis}

Mechanical strength of the polymer filmwas measured by Instron 5560 Tensile Testing Machine. Film thickness was $1 \mathrm{~mm}$, width $3.14 \mathrm{~mm}$ and length of each specimen was $19 \mathrm{~mm}$.

\section{RESULTS \& DISCUSSION}

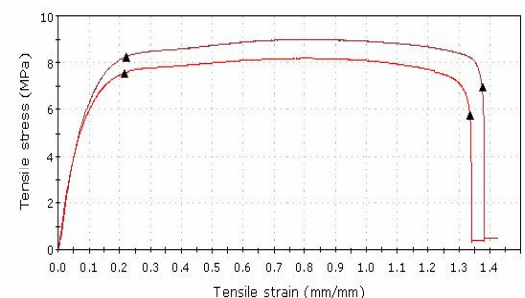

Figure 1 Tensile stress-strain curve for Pure Polyethylene. Tensile Stress at Yield is 7.93 MPa.

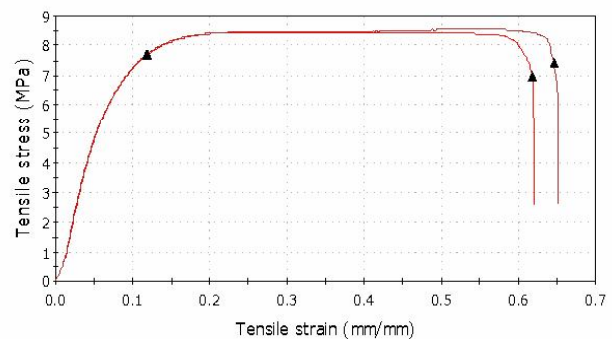

Figure 2 Tensile stress-strain curve for a mixture $10 \%$ starch and 90\% Polyethylene. Tensile Stress at Yield is $7.685 \mathrm{MPa}$.

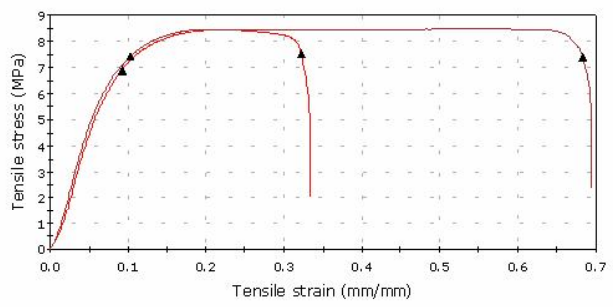

Sample

Figure 3 Tensile stress-strain curve for a mixture $20 \%$ starch and $80 \%$ Polyethylene. Tensile Stress at Yield is 7.17 MPa.

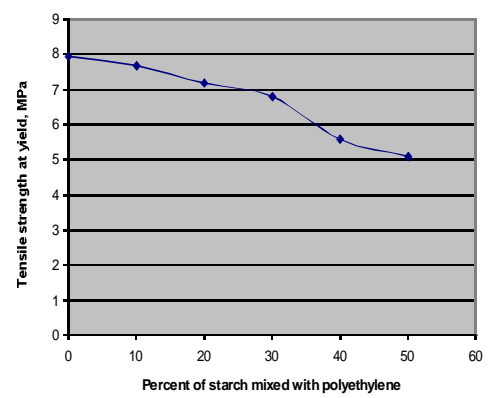

Figure 5 Variation of tensile stress at yield with addition of starch into polyethylene.

From this figure, it is clear that with the addition of starch mechanical strength decreases only slightly upto $20 \%$ but after that sample looses its strength significantly and cannot be used as shopping bag. 


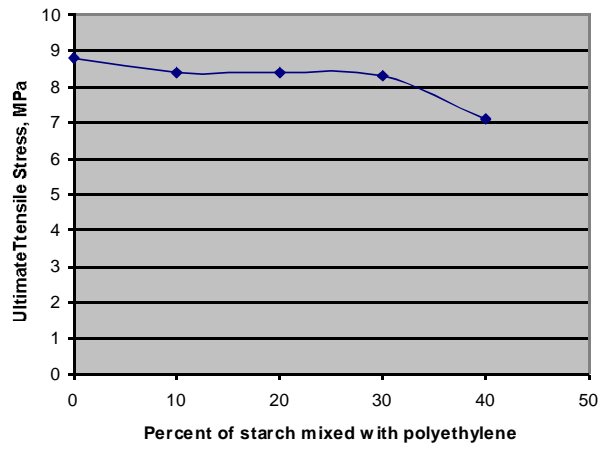

Figure 5 Variation of ultimate tensile stress with addition of starch into polyethylene.

From this figure, it is clear that with the addition of starch mechanical strength decreases sharply upto $10 \%$ and 15 to $25 \%$ it varies very little but after $30 \%$ sample looses its strength significantly and cannot be used as shopping bag.

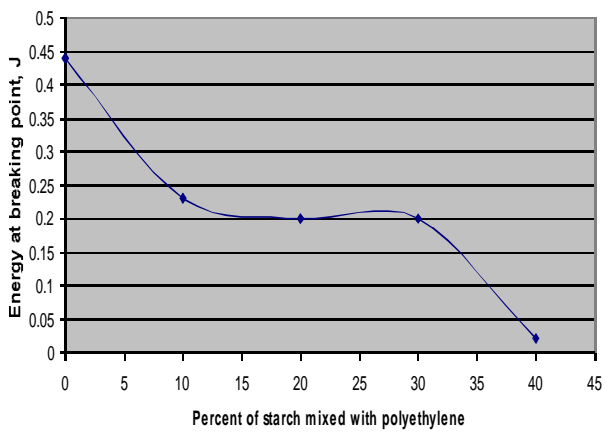

Figure $\supset$ Variation of energy at breaking point with addition of starch into polyethylene.

From this figure, it is clear that with the addition of starch mechanical strength decreases sharply upto $10 \%$ and 15 to $20 \%$ it varies very little but after $30 \%$ sample looses its strength significantly and cannot be used as shopping bag.

\section{CONCLUSION}

From the mechanical strength testing, we conclude the following:

1. With the addition of starch mechanical strength decreases.
2. Mechanical strength does not decrease significantly upto $25 \%$ and can be added in the shopping bag without any doubt.

3. After $35 \%$ sample looses its strength significantly and cannot be used as shopping bag.

4. As biodegradation rate increases with starch addition, 25 to $35 \%$ starch can be added safely in the plastic shopping bag.

\section{Acknowledgements}

This work was funded by King Abdul Aziz City for Science and Technology (KACST) (Grant Number:7925).

\section{References}

1. Starch/Stärke 1990, 42, 123-130.

2. ExcelPlas (2003) "The impacts of degradable plastic bags in Australia", Final Report to Department of the Environment and Heritage, Australia, Centre for Design at RMIT, Nolan-ITU, September.

3. Roldan-Carrillo $\mathrm{T}$; Rodriguez-Vazquez R; DiazCervantes D; Vazquez-Torres H; Manzur-Guzman A; Torres-Dominguez A (2003) "Starch-based plastic polymer degradation by the white rot fungus Phanerochaete chrysosporium grown on sugarcane bagasse pith: enzyme production, Bioresource technology 86(1), 1-5.

4. Kulshreshtha, Anand Kumar; Awasthi, Santosh Kumar. (1998), "Eco-friendly plastics for a niche market", Popular Plastics \& Packaging 43(11), 53-62.

5. Sitohy, Mahmoud Z.; Ramadan, Mohamed F. (2001) Biochemistry Dept., "Degradability of different phosphorylated starches and thermoplastic films prepared from corn starch phosphomonoesters" Starch/Staerke 53(7), 317-322.

6. Roper, Harald; Koch, Helmut. Gruppo Ferruzzi, (1990), "The role of starch in biodegradable thermoplastic materials, Starch/Staerke 42(4), 123-30. 7. S. Thiebaud, J. Aburto, I. Alric, E. Borredon, D. Bikiaris, J. Prinos, and C. Panayiotou, J. Appl. Polym. Sci., 65, 705 (1997).

8. S. Lim, J. L. Jane, S. Rajagopalan, and P. A. Seib, Biotechnol.Prog., 8, 51 (1992). 